\title{
"Lugares de memoria" a carón dun educador en Compostela e noutros pagos (1976-2010): Herminio Barreiro Rodríguez ${ }^{1}$
}

\author{
Vicente PEÑA SAAVEDRA \\ Universidade de Santiago de Compostela
}

\section{Fonseca máter: primeiro acubillo}

De Fonseca ao Monte da Condesa con recalada en Xoán XXIII. Ese foi o itinerario académico do profesor Herminio Barreiro en Compostela, que algúns dos que aquí estamos gozamos do privilexio de compartir canda el, total ou parcialmente. Neste mesmo fermoso e memorable, por tantos motivos, pazo de Fonseca, non lonxe de onde agora nos atopamos -claustro e xardíns por medio- principiaba o seu labor docente, formativo e educador. O ano 1976 enfiaba o seu treito final e daba comezo un novo curso no que el se iniciaba impartindo Teoría da Educación, materia específica da Sección de Pedagoxía, correspondente ao segundo ano da licenciatura en Filosofía e Ciencias da Educación, carreira por entón única, pero de configuración parcialmente diversificada e con perfís de triple desembocadura, que nese intre acollía á súa cuarta promoción. Lembro con meridiana claridade aquela aula lúgubre de chan en escaleira a ambos lados, provista de mouras e rancias bancadas, onde aló embaixo, nun estrado que máis ben semellaba un foso -aínda que se cadra constituía tamén un magnífico observatorio panóptico-, oficiaba as tarefas profesorais o noso homenaxeado, no horario vespertino, case de sobremesa, que se lle adxudicara.

Se a memoria non me engana, aquel 1976-1977 derivou nun curso de tránsito algo máis atípico que os que arribarían logo, pois dos oito meses lectivos programados, só tivemos clase -con relativa continuidade- arredor de dous. Corrían tempos turbulentos, nos que sentíamos a impresión de que todo estaba a suceder por primeira vez. De que os problemas se amoreaban. $E$ de que a protesta, o paro, a folga e os comunicados dos «abaixo asinantes» ou a adhesión dos que silandeiramente, tímidos e apoucados, nos sumabamos ao movemento reivindicativo, eran os únicos mecanismos dos cales se dispoñía

1 Texto lido polo autor no acto académico de homenaxe póstuma, celebrado na memoria e honra do prof. Herminio Barreiro Rodríguez, no Salón Nobre do Colexio de Fonseca da Universidade de Santiago de Compostela, o 14 de abril de 2011. A homenaxe foi promovida polo Departamento de Teoría da Educación, Historia da Educación e Pedagoxía Social, a que pertencía o citado profesor, sumándose a el a Facultade de Ciencias da Educación. A USC adheriuse á solemnidade concedéndolle a insignia de ouro da institución ao que fóra o seu membro docente durante cerca de sete lustros. A condecoración recollérona de mans do reitor e do director do devandito departamento a súa viúva e o seu fillo. 
para conter ou reorientar determinacións impositivas que viñan prescritas, case sempre, dende instancias alleas a aquel mundo doméstico, tan trepidante e vertixinoso, no que á espreita conviviamos. Pero todos estes altercados e outra morea de situacións de arroutada estampía, que agora repousan dormentes no imaxinario, non impedían que, malia a intermitente suspensión das clases, permanecésemos activos na orde académica, cando menos nalgunhas materias que espertaban entre boa parte do estudantado maior interese, por diferentes razóns. Unha delas Teoría da Educación. Convén subliñar -se ben moitos e moitas de vostedes xa o saben- que por aquelas datas apenas dispoñiamos de manuais desta disciplina, co rótulo acaído propio dela. Nin na biblioteca da Sección, embrionaria e minúscula, en proceso de crecemento ao ralentí e só episodicamente visitada por un alumnado adoito desafeito a tales mesteres de consulta bibliográfica directa. Nin tampouco nas mesmas librerías da contorna, onde resultaba difícil atopar unha peza tan degoirada como inexistente para poder mercala de forma particular, acotío con algún esforzo e nunca sen renuncias. Así pois, cumpría botarlle inventiva e intelixencia ao asunto, canda unha alta dose de «autodidactismo" guiado.

A sorte veunos dada pola presenza de Herminio Barreiro entre nós. El, recorrendo ao seu ateigado fardel de lecturas múltiples e ben dixeridas dende a mocidade -como corrobora en Recordar doe (2008)- e espigando artigos, pasaxes e textos de aquí e de acolá, lograra reunir un feixe de pezas para, na singradura do treito curto, encher de contido o temario daquela materia e facérnola atractiva e útil á maioría de cantos asistiamos a primeiras horas da tarde ás súas exposicións maxistrais e dialogadas, case corais, cando as volubles e dubidosas circunstancias cotiáns así nolo permitían. Ao principio, viña cada día repleto dun brazado de libros con marcas de papel en numerosas páxinas e unha gavela de medias cuartillas ['octavillas'] (que o dicionario de galego me obriga a traducir por 'panfletos', deturpando ou non -iquen sabe, pero tanto ten!- o seu contido e imprimíndolles unha nesgada connotación ideolóxica de signo axitador e propagandístico -jcanto lle gustaba a Herminio autodefinirse coa etiqueta de "axit-prop», que tamén lle outorgaba con respecto e agarimo ao seu admirado referente pedagóxico don Lorenzo Luzuriaga-). Medias cuartillas - dicíalles eu- con notas e apuntes que, supoñiamos, axudaban a lle dar armazón, cerna e sustento a un sólido discurso e servíanlle de apoio documental para desenvolver un guión, que ao comezo nos tiña nitidamente esbozado. Logo xa, non sei se nese mesmo ano ou nos seguintes, todas aquelas anotacións de singular grafía, acabaron por tomaren corpo, convenientemente arrequecidas e actualizadas, tempada a tempada, nuns cadernos de pastas duras, cor violeta rosáceas e formato vertical grande que, curiosamente, por imperativo docente eu usara con anterioridade en Linguaxe Matemática cando facía COU. Alí, nas súas follas, íase condensando a esencia dunha materia que só el era quen de descifrar para poñela ao noso alcance con verbas intelixibles.

Naquelas sesións de afluencia cada vez máis asidua e multitudinaria, non podía faltar o fume dos Celtas longos sen filtro que saboreaba con padal gorentoso ao compás das palabras precisas, mornas e luminosas, animadas pola xesticulación do corpo enteiro, mentres permanecía sentado, sempre sentado, perfumando e caldeando coas fumaredas e as frases que saían da súa boca, un ambiente receptivo e propicio para conectar con 
cada un e cada unha de nós -itan iguais e tan distintos!- e facer efectiva a comunicación sedutora que cobizaba. Eis o segredo xerminal e propedéutico da ensinanza e da intervención pedagóxicas. «Instruír deleitando", pregoaba o popular lema do célebre editor e manualista español Saturnino Calleja. ¡Coñecía de corrido cal era a chave mestra do oficio! Sabíao á perfección igualmente Herminio, como anos despois desvelaría ao escribir: «sinto moito non ter sido capaz de comunicar deleitando. ¡Quen poidera!» (Retallos para un tempo distinto, 1992: 10), queixa -ao meu ver- retórica e infundada, posto que conseguiu coma ninguén entretecer co seu alumnado, curso tras curso, andaina a andaina, unha auténtica comunicación pedagóxica, dende a empatía, o entusiasmo, a fascinación e a complicidade. Porén, mantiña a convicción de que, en xeral, non abondaba con ser un bo comunicador: "A la larga -engadía noutro dos seus artigos- lo que se comunica termina por imponerse». E continuaba: "Yo no estoy de acuerdo con quienes opinan que lo importante es comunicar bien, independientemente del objeto mismo de la comunicación. No estoy de acuerdo con eso de que hay buenos comunicadores y malos comunicadores y lo demás no cuenta. En todo caso, eso puede ser así en un determinado momento, pero, al final, la máscara termina por caer... Eso sí, un buen comunicador tiene ya las armas de la convicción y la persuasión preparadas de antemano y procura sacarles todo su partido". E remataba: «Pero sigue siendo fundamental -y, a veces, decisivo- 'lo que se dice' y no sólo 'cómo se dice lo que se dice'» (ibid: 146; orixinal de 1990).

Estaba no certo. $E$ por iso afanábase na procura de renovados recursos para 0 tratamento dos contidos, véndose no compromiso de facer, en moitas ocasións, da necesidade pericia e virtude. A perspectiva temporal, hoxe permíteme comprendelo con diáfana lucidez.

Emporiso, segundo lles anticipei, naquel ano auroral para el como docente nesta universidade, as clases na nosa Facultade non se prodigaron nin moito menos discorreron dun xeito normalizado e regular, por mor dos abondosos atrancos que decote nos atafegaban a uns (profesorado) ou a outros (alumnado), cando non a todos. E para conciliar 0 dereito á folga coa indispensable formación que nos cumpría, Herminio ideou e suxeriunos un procedemento, de voluntaria recorrencia, que consistía en proseguir realizando, pola nosa conta, os traballos de elección libre e execución individual ou por equipos sobre epígrafes, cuestións e tópicos relacionados coa materia, ademais de recensións de obras vinculadas a ela, que en canto lle concernía continuaría tutelando de forma titorizada. Por esta vía, lembro térmonos achegado a obras homónimas, pero de concepción e temáticas moi dispares entre elas, como a clásica Teoría de la educación do pedagogo diltheyano Hermann Nohl, editada por Losada (selo de especial predilección para o Prof. Barreiro), ou a do institucionalista Michel Lobrot da editorial Fontanella.

Periodicamente acudiamos ao seu despacho compartido, situado nos sotos deste inmoble fonsequiano, conxunción engarzada de colexio, facultade, parlamento e biblioteca. E alí, no marco dunhas sesións de atención exquisita e próxima, cálida e incentivante, facilitábanos as orientacións requiridas para afrontar os nosos traballos. De aí arranca, penso eu, o xermolo daquela fermosa experiencia ulterior, "dun curso moi especial», conforme el 
a catalogou, que se viu incitado a emprender e que relata polo miúdo no opúsculo Memoria crítica da escola desde a universidade (2004), o cal hoxe se reedita e entrega aos asistentes a este acto a modo de aloumiño e como simbólico -aínda que modesto- tributo de enaltecemento e honra á figura do homenaxeado, nestes días de treboadas, conmocións e incertezas.

Ao ano seguinte (1977-1978) recuncou con nós, pero para explicarnos unha das materias á que permaneceu vinculado durante máis dunha década: Historia da Educación I, que lla impartía ao alumnado de terceiro e de adaptación e abranguía dende as orixes da "educación difusa» no amencer das civilizacións até a "primeira revolución escolar moderna» do século XVII, unha dilatada singradura para un intervalo de tempo escolar de cativo tramo. A súa preparación previa (académica e máis aínda paraacadémica), 0 caudal de lecturas acumulado e sedimentado e a mentalidade hermenéutica e crítica que nel se fora modelando, facíano nomeadamente idóneo para responsabilizarse das disciplinas históricas da área pedagóxica. Da noción que albergaba e propugnaba da Historia deixou constancia en varias publicacións, tanto divulgativas como especializadas. Nunha das primeiras sostiña: «Aunque parezca paradójico, en el fondo, la Historia como ciencia, más que ocuparse del pasado, tiene siempre en cuenta el presente y, sobre todo, manifiesta una decidida vocación por el futuro». E proseguía, logo de citar ao seu apreciado e frecuentemente recomendado investigador hispanista Pierre Vilar: «En realidad, el objetivo principal de la historia debiera consistir en orientar a los seres humanos a la hora de tomar el camino más justo o el camino mejor, en su andadura social. Cualquier otra finalidad de la ciencia histórica es pura elucubración inerte y no significativa, erudición ociosa de lo que ya está definitivamente muerto" -todo isto resultaba doado transvasalo á Historia da Educación-, para rematar a súa arenga a prol da póla matriz con este rotundo aserto: «hoy, únicamente desprecian la Historia aquellas personas que ignoran que para estar en la vanguardia de cualquier disciplina 0 actividad, lo primero que hay que conocer, como muy bien decía Einstein, es precisamente la historia de la propia actividad o disciplina...” (Retallos, 148-149, orixinal de 1991).

As clases aloxáronse daquela nunha aula do andar superior, máis clara, moderna e luminosa ca do curso pasado, pero non por iso moito máis confortable. 0 método de ensinanza que empregara con nós o ano anterior o mantivo, aínda que con lixeiras variacións. Por exemplo, deunos a opción de escoller algúns temas, epígrafes ou apartados do programa, a fin de que os elaborásemos de maneira individual ou por equipos e logo de seren revisados por el os informes, se así o acordabamos, proceder á súa presentación aos demais compañeiros e compañeiras da clase. Se a memoria non me falla, era a primeira vez que na universidade se nos ofrecía tan alta cota de participación na construción e exposición dos contidos de parte dunha materia. Polo que recordo, a experiencia rexistrou unha acollida desigual. As inseguridades e os medos roldaban nas nosas cabezas e retraíannos á hora de tomar decisións.

O caso é que varios acabamos por aceptar a proposta e enseguida puxémonos mans á obra. Con máis dilixencia uns ca outros, porque na realización e, sobre todo, na transmisión das unidades monográficas conviña acomodarse á orde na que aparecían os enun- 
ciados no temario, de forma que non se sucedesen dun xeito atrapallado, caótico e, en suma, pouco pedagóxico. Lembro que o grupo no que me integrei escollemos os puntos cos que se abría a oferta programática. Isto é: «A educación nos pobos primitivos e nas civilizacións preclásicas do Antigo Oriente», máis ou menos nestes termos. E como ocorría e segue a acontecer en case todos os grupos, fixemos unha división interna do traballo para poder operativizar a encomenda. A min correspondeume abeirar a vertente do cimal [«A educación nos pobos primitivos»], non sei se por escolla, sorteo ou designación. A verdade é que me sentín moi cómodo con aquel pequeno núcleo de apertura, ao que só algúns manuais lle dedicaban un sucinta atención, pero sobre o cal se podían obter datos complementarios de relevo en diversas obras antropolóxicas, unha mínima parte das cales xa manexaramos, a vista de paxaro, o ano precedente da man do profesor Javier Sanmartín. Con todo isto e as orientacións debidas do noso titor emprendemos a aventura. Ao cabo, a experiencia a min resultoume moi gratificante e non menos formativa, malia a lóxica tensión que toda práctica iniciática comporta e, en maior medida, se require comparecer ante un auditorio, por afín e benevolente que este sexa. Pero nisto haberá que pararse logo cun chisco de vagar. Boa proba da pegada satisfactoria que deixou en min a experiencia é que xa non abandonaría o tema durante os anos sucesivos, até chegar a se converter no punto de partida da miña futura tesiña. Por esta vía tamén perdurou tanto a vinculación persoal con Herminio Barreiro como a mesma decantación preferente cara á Historia da Educación.

A diferenza do que acaecera o curso anterior con Teoría da Educación, para o tratamento desta nova materia xa se dispuña dun amplo repertorio de manuais -uns clásicos e outros de recente aparición-, así como dun elenco de monografías e obras de autoresfonte relativamente copioso. Dos textos máis accesibles para nós había un par deles que Herminio nos aconsellou con especial empeño e fervor: a Historia de la educación y de la pedagogía de Lorenzo Luzuriaga, con dedicatoria a Manuel B. Cossío (aparecida en Bos Aires, baixo o emblemático selo de Editorial Losada, e que en 1976 ía pola undécima edición). «Un manual o de D. Lorenzo -escribiría o agora homenaxeado cinco lustros despois, cando o libro mantiña en parte a súa vixencia, que aínda arestora non perdeu- que leva en si toda a solera e todo o sentimento tráxico do desgarrado século XX en España, aquí, na propia 'pel de touro' e alá, no exilio ultramarino» (Memoria crítica, 2004: 17). E canda el, Educación y lucha de clases, do proteico intelectual e activista arxentino Aníbal Ponce, «un libro que ten un título que é como un anuncio, unha proclama ou un panfleto revolucionario», subliña Herminio, para agregar decontado: «un ensaio crítico marxista espléndido, profundo e pedagóxico a un tempo, cheo de ritmo e de vivacidade», e concluír: «Un libro, en fin, que é como un viaxe sereno, triste e alegre, un pouco escéptico si se quere (a propósito da capacidade socialmente transformadora da educación e dos sistemas educativos en xeral), pero, de calquera maneira, sorprendente, magnífico e sempre maravilloso, pola historia da educación universal...» (Memoria crítica, 2004: 18-19). Esa inmellorable opinión que lle merecían os «apuntes» tomados a partir das conferencias universitarias de Ponce en Bos Aires era a que pretendía compartir con nós, decontino coas cartas boca arriba, e sen facer uso de ningún tipo de estratexia adoutrinante, proselitista ou impositiva. 
Aquel mesmo ano comezou a ensaiar co meu grupo -estou seguro de que xa o experimentara con outros- a aplicación do comentario de textos "como método de aprendizaxe e comunicación" e tamén como proba de avaliación, deixando ao noso dispor os materiais de consulta que se nos antollaran. Década e media despois (1991), no «Limiar» dunha obra instrumental colectiva que tiven a honra de coordinar con el -e da cal no seu momento direi algo máis-, rememoraba así aqueles prolegómenos: "O comentario de textos en Historia da Educación xa é unha vella historia na nosa Facultade. Aquelo que nacera como primeiro e simple método de traballo, alá polos últimos 70 , en Fonseca, foi converténdose, co paso dos anos, nunha forma arraigada de análise histórica, case nunha 'especialidade' para as alumnas e os alumnos de Historia da Educación, nos seus respectivos ámbitos de traballo: épocas antiga, medieval e renacentista, para a Historia da Educación I e período moderno e contemporáneo para a Historia da Educación II». E preguntábase logo: «Por que, pois, o comentario de textos como sistema de traballo académico?». Respondendo de inmediato: «En primeiro lugar, polo feito de que comentar un texto é, antes que nada, unha invitación á lectura reflexiva e sosegada. A esa lectura que Tierno Galván comparaba coa maneira de beber que teñen as galiñas: lectura coa cabeza baixa dun pequeno párrafo -embuchar- e meditación posterior coa cabeza erguida -abalar-». Para sen detemento argumentar: "Comentar un texto é sempre un estupendo e san exercicio de imaxinación intelectual e de aprendizaxe versátil, libre e anticompulsiva. Pretende fuxir da mecánica dos exámenes tradicionais, aínda que ás veces corra o risco de caer tamén nunha certa retórica pouco creativa. De calquera xeito, é unha das mellores maneiras de achegarse a unha visión 'interior' da Historia nos seus textos fundamentais, á 'verdade' da Historia das ideas e dos fenómenos educativos» (Historia da Educación: textos comentados, 1991: 1-2).

Das anteriores consideracións despréndese, sen esforzo, que a preocupación fundamental e prioritaria para o profesor Herminio Barreiro consistía en que o alumnado practicase unha modalidade de lectura á que, polo regular, non viña afeito, sequera co destreza debida. $O$ cultivo desta habilidade encamiñaríao a unha tarefa exploratoria no pensamento alleo, sen atrancos nin fronteiras, para a partir dese proceso comunicativo, dialóxico e de interacción, acabar suscitando ou facendo abrollar novas aprendizaxes. Alén das recorrentes e sobadas avaliacións e cualificacións, o obxectivo cardinal radicaba en que as pedagogas e os pedagogos do porvir fosen adquirindo as competencias necesarias -nada novo baixo o sol de Boloña- para dilucidar e comprender dende os soportes documentais máis comúns o devir histórico da educación nas súas diversas manifestacións. Ese sería un tesouro, non só instrumental, que permanecería vizoso para sempre naquelas e naqueles que 0 atinxiran, en tanto a razón os asistise.

O curso seguinte (1978-1979), o derradeiro aquí en Fonseca, o grupo da miña promoción, que por entón chegaba a cuarto, non tivo aulas con Herminio. Pero adoito atopabámolo ou procurabamos coincidir adrede co noso carismático profesor mentres, entre clase e clase, descansaba sentado nos bancos de pedra que hai arrimados aos muros do claustro deste nobre edificio, degustando con indisimulado pracer un Ducados -ou dous, se o tempo da folganza o permitía- e á agarda de que alguén fose onda el para preguntarlle como ía todo e xa a partir de aí enliñar o fío dunha conversa de rumbos inescrutables e 
tempos indefinidos. Plácido, o bedel máis curtido do centro, non deixaba de manterse ao axexo. Eu, e outros moitos coma min, acostumábamos visitalo no seu despacho, de cando en vez, por motivos de traballo ou doutra natureza que resultaría prolixo aquí detallar.

\section{Nos lindeiros do Campus Norte: en tránsito}

Cando deu comezo o curso 1979-1980, a mudanza levounos ás novas, pero reducidas e inhóspitas dependencias de Xoán XXIII, a rentes da Escola de Formación do Profesorado, unha parte substancial do futuro común. Nunca coma daquela e durante un quinquenio -cómpre lembralo por se de algo servise-, as dúas gallas escindidas do tronco que forma a nosa actual Facultade estiveron fisicamente tan pretas. Mais entón as circunstancias non eran propicias para maridaxes, integracións ou fusións. ¡Quen sabe cando os ventos volverán virar ao noso favor!

Alí, nunha aula de rabenada altura, con fiestras que miraban cara o monte Pedroso, ao que nós irrespectuosamente lle dabamos as costas, encontrámonos doutra volta co profesor Herminio Barreiro, quen nos acompañaría no derradeiro ano da licenciatura. Había que completar aquela Historia da Educación que principiaramos en terceiro ou no curso de adaptación. Sete meses por diante, moito máis acougados, para mergullarnos nun ciclo histórico enormemente denso, axitado e atractivo que, en termos xerais, abranguía dende a llustración francesa até a Segunda República española. Un pasado que se facía case presente e que Herminio nolo poñía ao alcance da man. Voz e textos. A forza da palabra, as fontes amansadas e os manuais escolmados abondábanlle como recursos docentes para procurar entusiasmarnos cos contidos esenciais da materia. Así, sen outro aditamento tecnolóxico que -ocórreseme agora-, talvez, se convertese nun estorbo que lle faría máis mal que ben. $\mathrm{O}$ verbo espido. Firme pero doce. Radical pero balsámico. Rotundo pero comprensivo. Insubmiso pero tolerante. Heterodoxo pero conciliador. Utópico pero posibilista. E arreo, fronte ao afundimento, desdramatizador.

Os vellos manuais aínda non caducaran (Ponce, Luzuriaga...), pero viran a luz algúns outros -non demasiados, sen embargo- para o tratamento da contemporaneidade. Maior era o número de monografías sobre períodos ou etapas concretas. No caso español, por exemplo, a Educación na Segunda República converterase nun potente foco de atención (Pérez Galán, Molero Pintado, Lozano Seijas...); como tamén a Institución Libre de Enseñanza (ILE) o estaba a ser dende a iniciática obra de Vicente Cacho Viu (1962) -que vén de recobrar actualidade nos nosos días- e en máis alto grao co gallo do seu centenario fundacional (1976). Contabamos ademais con outros dous monumentos historiográficos de extraordinaria notoriedade, o texto de Yvonne Turin, La educación y la escuela en España de 1874 a 1902 (1967) e o de Ma - Dolores Gómez Molleda, Los Reformadores de la España contemporánea (1966). Sen omitir a anticipatoria monografía de Julio Ruiz Berrio, Política escolar de España en el siglo XIX, 1808-1833 (1970). Á súa vez, dende o abrente da década dos 70 estaban a recibirse os revulsivos do país veciño [Baudelot-Establet, La escuela capitalista en Francia (1975); Bourdieu-Passeron, La Reproducción (1977)]. E por acó agromaba algún que outro correlato específico de notable pegada como Escuela, 
ideología y clases sociales en España (1976) de Carlos Lerena, "o mellor sociólogo da educación dos últimos anos en España, [...] un paradigma da investigación pedagóxica, un mestre», segundo palabras do homenaxeado (Retallos, 1992: 31).

Así e todo, o profesor responsable da materia que nos ocupa, continuaba a preservar -por sorte para os seus discípulos- moitos atributos do «mestre artesán», en afortunada expresión categorizadora do catedrático de Historia da Educación da Universidade de Florencia, Antonio Santoni Rugiu, quen faleceu cando se preparaba a edición desta laudatio. En efecto, Herminio seguiu escolmando e reconstruíndo materiais de moi variada procedencia coa idea de facernos máis doada, compracente, útil e formativa a incursión naquel ámbito de coñecemento que non para todos posuía igual nin similar atractivo.

Daquela, e tamén xa antes, gustaba de acompañar aos estudantes que o convidaban a compartir parola, mesa e algo que levar á boca fóra do recinto académico. As conversas alongábanse sen présa nin vontade de fin, encadeando un tema con outro. Dende o máis prosaico e mundano até o máis escollido e sublime. Escoitabamos en maior medida que falabamos. Fascinábanos oílo parolar. E tiñamos a sensación de estar a aprender sempre algo inédito del. Sendo así, non podía espertar en nós máis que un extraordinario respecto e unha fonda admiración. Sen decatármonos, participabamos ao seu carón nun auténtico proceso educativo que nos facía sentir cada vez un pouco mellor e, mesmo, un pouco mellores.

Rematada a licenciatura, había que enxergar ou, cando menos, imaxinar un novo horizonte cos oportunos itinerarios que cara el nos conduciran. Pola miña parte, xa decidira, se cadra de forma prematura, que de maneira inmediata tiña que concluír unha tesiña na cal comezara a dar os primeiros pasos, coa ollada posta, case coma unha fixación, na permanencia na universidade, seducido por aquel modelo docente encarnado por Herminio e no que decote me ollaba. Xuntos acordaramos, había tempo, o tema da investigación, tomando como punto de partida o traballo de curso que fixera en terceiro. E buscámoslle un título para inscribila. Aínda hoxe é o día en que, cando reparo no rótulo elixido, non deixa de sorprenderme -mesmo de ruborizarme- a miña propia ousadía. Pervivencia de formas primitivas e cambio socioeducacional no medio rural galego. Así quedou enunciado o título. Para afrontar o asunto disporía das orientacións tanto do profesor Barreiro Rodríguez como do profesor da sección irmá de Filosofía, Rodríguez Campos, experto en Antropoloxía, recaendo formalmente a dirección académica no Dr. Carlos Rosales, valedor nestes mesteres, por entón, de tantos de nós. Lembro con irremediable nostalxia aquel verán do 80 no que Herminio, ao tempo que avanzaba na súa tese de doutoramento sobre Lorenzo Luzuriaga, me acollía no fogar familiar da rúa Alférez Provisional (hoxe Santiago del Estero). E alí, sempre coas esmeradas atencións da súa compañeira Merche, mentres Sonia e David se ocupaban das súas cousas, eu recibía as suxestións oportunas para levar a bo porto un proxecto que me tiña engaiolado.

Caio na conta, ao redactar estas liñas, de que non sendo xa momentos propicios aqueles do solpor dos 70 e o alborexar dos 80 para «facer escola» dende a universidade, como puidera ter ocorrido noutrora, o hoxe homenaxeado soubo fomentar a sensibilidade 
histórica no alumnado das sucesivas promocións. Quizais máis no das primeiras que no das últimas, aínda que para confirmar esta persoal intuición requiriríanse as testificacións acreditadas doutras moitas voces. Só nuns poucos acabaría por callar a sensibilidade en vocación e esta, por azares e empeños, en profesión. Os espazos para unha especialidade tan concreta como a da Historia da Educación, por acó, nunca superaron as estreiteces dunha leira de minifundio, en consonancia coa tradición da estrutura territorial do país que tanto nos marca. Pero o verdadeiramente salientable non é isto, senón o feito de que a cantos frecuentamos as súas clases e o acompañamos fóra delas, ensinounos a "pensar historicamente» a realidade educativa, para dicilo ao abeiro das atinadas palabras de Pierre Vilar, a quen el tanto admirou e nos citou.

No decorrer dos primeiros 80 , sen deixar de ser aprendiz do seu permanente maxisterio, fun adquirindo de xeito paseniño a condición de compañeiro de Departamento. Uns anos difíciles, por cuestións que non vén ao caso agora evocar. Pero inzados tamén de episodios gozosos, sorprendentes, únicos. Como aquel luns, 23 de febreiro de 1981 que recentemente -tres décadas despois- tanto se rememorou e que para nós, alumnado e profesorado de Pedagoxía, que andabamos por Xoán XXIII, tivo unha significación moi especial, da cal Herminio se fixo eco máis tarde nun artigo publicado na Revista Galega de Educación (no 8, 1989: 20) e compilado en Retallos para un tempo distinto (1992: 31-33). Daba comezo a Semana de Educación que o estudantado organizaba co apoio do centro e outras entidades externas. $O$ convidado de honra era nada menos que Carlos Lerena, a quen xa antes amentei. Así glosaba Herminio algúns intres da senlleira xornada: «Non esquenceremos nunca aquel $23 \mathrm{~F}$ con Lerena en Santiago. Lerena impartindo un seminario coa aula abarrotada de estudiantes e Tejero entrando no congreso. Lerena dándonos unha densa conferencia sobre o oficio do mestre e os tanques de Miláns del Boch paseándose por Valencia. Con Lerena de bares por Compostela e o anuncio inminente da aparición de El Rey na TV. Inolvidable. // Ese día establecímo-la nosa amistade con Carlos Lerena" (Retallos, 1992: 32). O seu relato abonda. Cada quen que lle poña o resto da propia colleita ou da crónica que lle contaron as testemuñas directas.

En maio de 1982 acadou o título de doutor coa tese titulada Aportaciones de Lorenzo Luzuriaga a la renovación educativa en España (1889-1936), dirixida polo Dr. Julio Ruiz Berrio -quen, non por casualidade, tamén acabaría orientando a miña- e coa que obtivo a máxima cualificación. Con anterioridade alentara a introducirse no tema ao prof. Miguel $A$. Santos Rego, quen lle dedicou á obra pedagóxica do autor manchego a súa tesiña (1978).

Nese mesmo ano (1982), todos cantos daquela estabamos a investigar no campo da historia da educación dende a Universidade de Santiago -entón única universidade galega- participamos nunha actividade congresual que non cabe adxectivar máis que de iniciática e de prometedora, tanto para nós coma para a nosa área de estudo. Refírome ao denominado I Coloquio de Historia da Educación (a esa altura sen nación nominal de seu), organizado pola "Sección de Historia de la Educación» da "Sociedad Española de Pedagogía» e que se celebrou en Alcalá de Henares, en plena campaña electoral que conduciría ao PSOE ao trunfo nas urnas. 
Á marxe do que comportou nos planos científico, académico e corporativo aquel precursor encontro, para os que de aquí asistimos e sobre todo para os que tiñamos menos mundo -eu case ningún- representou unha apertura ao exterior que se viu arrequecida cunha viaxe histórico-educativa e de acentuado carimbo pedagóxico, absolutamente inesquecible, polo menos ao meu particular entender. Por avezado no destino e nos camiños, a Herminio correspondeulle fixar ou bosquexar as rutas de ida e volta, así como os lugares de repouso e visita. Adoitaba documentarse antes de saír, fornecéndose de guías e libros varios que levaba na guanteira do 127 branco, sempre cheo de ocupantes que 0 acompañaban, e ao cal polo regular seguían outros utilitarios en caravana. De cando en vez convidábanos a ler en voz alta algunha pasaxe relativa á localidade que atravesabamos ou que se atopaba próxima. Maxisterio vivo de excepcional cicerone. Sabiamos cando saíamos, pero nunca con certeza por onde iriamos, canto tempo permaneceriamos deambulando por pobos e estradas e o día no que volveriamos á casa. A improvisación sobre o terreo, a aventura e os periplos alternativos eran algunhas das súas grandes paixóns viaxeiras. Sentíase emocionado, eufórico, pletórico cando emprendía unha nova singradura. E esas pulsións ían en crecente progresión.

A peripecia posuía tamén banda sonora de seu, polifónica no percorrido, pero pouco variable na saída de Galicia e na entrada de regreso á Terra. Os himnos predilectos eran polo común, nestes dous enclaves fronteirizos, algunhas das pezas máis populares do Cuco de Velle ou outros cantos patrióticos de sona dispar, enlatados en cintas de casete, á antiga usanza.

Aquela primeira experiencia nos albores da estación outonal contou con estadía previa e postrema en Madrid cidade e nos seus arredores, escenarios onde Herminio se sentía, por razóns obvias, coma en Sisán (Ribadumia) ou en Compostela. Tratábase do Coloquio paralelo, que tanto nos aproveitou, en multitude de esferas, as cales aquí non poden ter cabida nin rexistro evocativo. Permítanme, en calquera caso, que lembre con brevidade para vostedes algúns dos memoriais que visitamos. Viña de ser trasladado 0 ano anterior, dende 0 exilio en Nova York ao Casón del Buen Retiro, o Guernica de Picasso, e alá nos levou como primicia. Nunca saberei dicir que me impresionou máis, se o cadro en si -iconografía encarnizada do terror- ou o ambiente de denso e rigoroso silencio que á beira del se palpaba. Acudimos tamén a algunhas dependencias do Museo del Prado. E a lugares menos monumentais pero de inequívoca simboloxía, por razóns ben distintas: as librerías Fuentetaja e Rubinos 1860, os cafés literarios Gijón e Lyon D'Ore unha morea de tascas tradicionais dos barrios máis castizos da vella vila e capital. Por suposto, de cerca ou de lonxe, algúns dos espazos de confluencia cotiá dos integrantes de Brais Pinto. E logo, ademais, non acertaría discernir se á ida ou á volta, fragmentos patrimoniais dun mosaico policromático de contrastados perfís, cunha potente carga alegórica como o mosteiro de $E I$ Escorial, o Valle de los Caídos (a maior fosa humana do franquismo) ou a Fonte de Cossío, no porto de La Morcuera, santuario laico dos institucionistas, que daquela esmorecía en ruínas e logo sería rehabilitada. Ao retorno, paradas técnicas na Gudiña ou en Verín, coa noite enriba; e ás portas da mañanciña, escala no Silencio de Lalín, recanto de veladores e insomnes. 
O circuíto lúdico e cultural de convivencia conxunta mantívose, con certas variacións na composición do colectivo e na xeografía dos roteiros, durante un cuarto de século (1982-2007). A derradeira expedición con el levounos a Guadalupe (Cáceres) en 2007. ¡Cantas crónicas e anecdotarios, entre a realidade e a ficción, daqueles peregrinares fican na memoria e no tinteiro como pouso do vivido! A ver se alguén, perito en letras, se anima a estampalos sobre o papel para relouco de todos.

\section{Nos confíns do Campus Sur: acougo e destino}

No curso 1983-1984 iniciei a miña colaboración docente efectiva co profesor Herminio Barreiro na materia Historia da Educación I. Ao principio só nalgúns seminarios, coma se dun adestramento se tratase. Que diso ía a cousa, pois non cabía sospeitar que fose doutro xeito, cando parte das penurias do lumbrigar comezaban a esvaecerse.

Pero contra o remate daquel bienio ocorreron dous feitos de grande calado na traxectoria universitaria de Herminio, e un deles -se cadra os dous- na de todos e todas nós. 0 primeiro consistiu en que o aquí homenaxeado accedeu á praza de profesor titular. A devecida e reivindicada estabilidade profesional, por fin consumábase para el. E o segundo estribou no traslado do edificio de Xoán XXIII ás novas dependencias na ladeira sur do Monte da Condesa, onde por aquelas datas aínda tiñamos veciñanza de raíz non universitaria. $A$ primeira casa de estudos propia con despachos máis confortables, aulas apreciablemente mellores e servizos comúns, coas outras dúas seccións, de maior amplitude e calidade. Foinos asignado cada o noso gabinete na mesma zona, porta con porta, a el, a Antón Costa e a min. E alí ficamos xa para sempre. Non sei se esta última palabra, cos tempos que corren de «acontecementos inesperados» (Memoria crítica, 2004: 12), experimentará variacións nas trasfegas de quen agora naqueles pagos moramos. Debo engadir que 1984, a Herminio, aínda lle deparaba outra grata e merecida sorpresa: a edición abreviada da súa tese, a cal viu logo a luz de forma íntegra en 1989, consagrándoo como a máxima autoridade española e universal experta en Lorenzo Luzuriaga.

Pouco despois de térmonos instalado no novo emprazamento, a nosa cooperación nas tarefas desenvolvidas co alumnado foise incrementando e afianzando. Aló polo curso 1986-1987 procedemos a realizar un reparto de funcións que abranguía a toda a disciplina de Historia da Educación (I e II) [terceiro, adaptación e quinto]. El ocupábase do tratamento das sucesivas etapas polas que discorreu a educación, e eu centrábame nos aspectos de carácter conceptual, teórico, epistemolóxico, documental e metodolóxico da materia, dedicándome tamén a orientar e supervisar os traballos de iniciación á investigación que lles suxeríamos aos estudantes. Esta dinámica mantívose mentres as condicións académicas o permitiron. Procurabamos que non houbese solapamento no noso labor, senón complementariedade. E el, coa impecable mestría que o distinguía, actuou sempre de maneira elegante, habelenciosa e discreta para que o alumnado non se vise na delicada e incómoda tesitura de establecer comparacións absurdas entre os dous profesores que compartíamos a mesma materia. De chegar a facelo, eu xa me podía dar por vencido e a miña carreira docente dificilmente tería garantías de continuidade naquel ámbito ou fenecería inerme nun treito de curto percorrido. 
Lembro que por entón, e en moitas outras ocasións até os derradeiros cursos que estivemos xuntos, abeirábame a Herminio para confesarlle os temores, as inseguridades e as tensións que a comparecencia na aula perante as mozas e os mozos das sucesivas promocións me orixinaba. E nun xesto de solidariedade ou de complicidade que a min me servía de lenitivo e me daba folgos para continuar, revelábame que a el ocorríalle algo semellante. A min custábame crelo, véndoo tan enteiro, convincente, fluído e documentado no seu impecable discurso. Mesmo parecía que estaba a recrear, cando non a repentizar, en cada sesión de clase un relato novo, tras innumerables horas de maina lectura e de concienciudo estudo. Pero vindo del non tiña máis remedio que admitilo sen reservas; porque, por outra banda, tamén me conviña, xa que me alentaba a proseguir, asumindo 0 arnaxe dos meus desasosegos. Logo, acabaría por corroborar a veracidade de todos aqueles síntomas de desacougo cando lía nas súas memorias confidencias deste teor: "Ao longo do tempo e co paso dos anos, na época dos exames, aló polos meses de maio e xuño (non tanto en setembro, onde o máis duro xa pasara), comecei a sentir unha especie de nerviosismo xeral e de ansiedade sintomática que tampouco me deixaría nunca máis". $\mathrm{E}$ decontado engade: "Nerviosismo e ansiedade intensos dende os dez aos vinte e tantos e máis, isto é, ao longo de toda a miña vida de estudante. Mais non só de estudante. Porque, unha vez rematados os estudos secundarios e universitarios, na miña etapa de profesor de ensino medio e mesmo despois, como profesor universitario, seguía a sentir esas mesmas emocións, asociadas sempre, como digo, a circunstancias sociais e ambientais desacougantes e asemade, estimulantes, competitivas e de tensión positiva. Primeiro gozaba e sufría como estudante e despois sufría e gozaba cos estudantes". E aínda reitera noutro parágrafo posterior: "Porque ese medo a ser examinado e a ter que render contas, ese medo escénico profundo, levaríao sempre comigo e remataría por facerse crónico, como discente e como docente, como estudante e como profesor" (Recordar doe, 2008: 73-74 e 89). ¡Canto alivia e reconforta verse retratado no relato intimista dun educador, compañeiro e amigo!

Unha pequena proba do traballo en común coa participación directa de 9 estudantes -boa parte deles hoxe ensinantes nas Universidades da Coruña e Santiago de Compostela-, durante a segunda metade da década dos 80 e principios dos 90 , figura na publicación que xuntos coordinamos e xa mencionei, titulada: Historia da Educación: textos comentados (1991 e 1993), de cuxa intención nodal el rendía conta nos seguintes termos: "A razón deste libro radica principalmente na súa practicidade. Preténdese ofrecer aquí un abano de textos comentados, de distintas épocas históricas, dende perspectivas tamén distintas e coa estilística máis diversa. En galego e en castelán. Sobre textos antigos e modernos. De pedagogos ilustres e de outros pensadores que abordan temáticas relacionadas con segmentos importantes da Historia da Educación. 0 espíritu renovador e a multiplicidade metodolóxica desta disciplina queren estar aquí presentes, aínda que a mostra resulte quizáis un pouco curta» (1991: 1). Alí mesmo formulaba "o firme propósito de publicar unha segunda entrega» (ibídem) que xa nunca houbo ocasión de facer realidade. No entanto el, coa vontade de poñer ao dispor do alumnado unha ferramenta na que percibía grandes potencialidades para a aprendizaxe, ocupouse do tema en numerosas ocasións, actuali- 
zando ideas que plasmara por vez primeira nun artigo en 1982 (Perspectivas Pedagógicas, 50: 309-320). Fortuitamente, ambos os dous canda o profesor Requejo compartimos páxinas do número da revista na que apareceu aquela versión príncipe.

Nos repositorios da memoria gardo con inmensa veneración, entre outras moitas anécdotas gratas da miña relación con Herminio, unha moi especial que, coa licencia de vostedes, me permitirei rescatar. Aconteceu o día da defensa da miña tese de doutoramento. Herminio, como secretario do tribunal foi o primeiro en abrir a quenda de intervencións. E para sorpresa e desconcerto de todas e todos -público incluído-comezou lendo uns versos dun mediocre poema meu, escrito e publicado nos anos da adolescencia, o cal conseguira recuperar sen dificultade facendo uso das súas arteiras mañas. Con ese acto de exhumación quería deixar constancia da xénese do meu interese polo tema da emigración. Para min era a primeira vez que oía os anacos dun texto literario -combativo, pero inxenuo e temerario- da miña autoría na voz doutra persoa. E o certo é que, trala lóxica turbación inicial, pareceume que as palabras por el recitadas gañaban moita calidade da que en si, na fonte nutricia, carecían. E quizabes non lle faltase razón ao identificar o berce daquela inquedanza social e intelectual, que iría motivando preocupacións futuras en min por un referente inequívoco da nosa historia, tamén no eido educativo. Alén da anécdota en si, o feito evidencia a calidade humana e intelectual dun universitario pleno que, inserindo a obra dun autor no seu contexto e ligándoa con outros factores e vertentes menos visibles da súa produción e da propia vida, procura atopar claves elucidantes e explicativas que se agochan na penumbra e empecen ou ensarillan procesos de intelección. Iso era, xustamente, o que tantas veces tratou de transmitirnos a nós nas aulas e fóra delas.

Dende o declinar dos 80 e máis aínda durante os 90 e, por extensión, na década de apertura do século actual, intensificouse moi sensiblemente tanto a produtividade científica de Herminio Barreiro como a participación en actividades culturais externas de extensión universitaria, sen por iso minguar a súa entrega á docencia, que sempre adoitamos salientar como a dedicación predilecta do noso homenaxeado, por máis que este tópico, se cadra, reclame algunha modulación segundo os ciclos e intersticios vitais. Ao seu criterio non había dúbida verbo da "misión da universidade», para expresalo con palabras de Ortega de quen, precisamente, recomendaba ao alumnado como texto de lectura e recensión o Libro de las Misiones. Pois ben, conforme escribía en maio de 1989: "A función da Universidade é a investigación -ésta sí en necesaria conexión co mundo productivo-, a ensinanza superior -formación de cuadros- e a capacidade de xenerar crítica cultural, económica, política e social, dunha maneira permanente. Función, pois, múltiple e diversa» (Retallos, 1992: 15). E só un mes despois retoma o tema e puntualiza: «Si é verdade eso de que o traballo universitario debe ser unha sabia combinación de docencia e investigación, non podemos esquencer que a pesares de todo, aínda é moito máis o que hai que ensinar que 0 que se pode investigar» (ibid: 28-29). E laiábase: "seguimos a ensinar mal o que outros investigan e o que eiquí mesmo se fai. A nosa pedagoxía segue a ser unha pedagoxía antigua...» (ibid: 29). Que cada quen lle poña o seu gran de area. 
Pero con independencia do peso relativo que se lle atribúa a unha e outra tarefa, por riba delas, continua e invariablemente debe situarse o alumnado. Da súa indefectible presenza no proceso educativo e da alta estima que lle tiña, velaquí algúns testemuños escolmados entre unha manchea de ponderacións dispersas arredor deste asunto.

De entrada, como aviso para navegantes despistados ou ao garete sostén que: "Os profesores e os dirixentes da Universidade deberían sentirse acotío entre os estudantes coma o peixe na auga». E arguméntao así: "Non o esquezamos: eles son a nosa única razón de ser. Giner de los Ríos dixo un día que podemos imaxinar unha Universidade sen medios; ou unha Universidade mesmo sen edificio; ou unha Universidade sen biblioteca, por exemplo; ou podemos chegar a pensar nunha Universidade incluso sen profesores (lembremos a vella Universidade de Boloña); pero o que non poderemos nunca é imaxinar unha Universidade sen estudantes. Porque eles son a esencia mesma da institución» (Memoria crítica, 2004: 14; ver tamén Recordar doe, 2008: 195).

Coa síndrome do andazo morriñento, pola arribada dun final de carreira, declara en vésperas do verán de 1991: "Os amantes da profesión saben que o ideal soñado e imposible de máis encegadora vocación pedagóxica consiste en poder estar con todo o alumnado a un tempo, todo o tempo... E poder seguir o seu traballo futuro nunha interrelación continua e permanente. Eis o ideal inacadable do 'ethos' educativo perfecto" (Retallos, 1992: 40-41).

E antes xa, en 1989, sentenciaba, tentando trasladar ao xentío a súa mensaxe de inconmensurable aprecio polos discentes: «non hai maneira de establecer unha 'comunicación pedagóxica' fonda e viva, se non se basa na máis alta consideración humá e no maior respeto por todos aqueles que están dispostos a aprender» (ibid: 24). Claro que, como el mesmo di: «Aprender é un deber» (ibid: 27). Pero esa obriga transita por vieiros moi desiguais en harmonía co clima afectuoso ou ríspeto que lle dea abrigo. En palabras de Herminio: "Cuando el estudiante que tiene sed de saber o el aprendiz que se desvive por dominar su oficio, encuentran la necesaria receptividad en sus maestros, se entregan por entero a su tarea. La relación pedagógica sólo cobra todo su sentido cuando existe una cierta forma de 'enamoramiento' entre el profesor y los alumnos» (ibid: 150). Así e todo, a relación ha ser bidireccional, pois como suxire o noso mentor: os alumnos senten «máis veces mesmo do que algúns pensan» que o profesor os necesita (Recordar doe, 2008: 135).

Noutra pasaxe datada a medio camiño entre algunhas das xa recollidas, ao ocuparse do labor académico do estudantado, desafógase e recoñece: «Alguien podrá tomarme por un bicho raro, pero el caso es que siento un placer especial con la lectura de los exámenes de mis alumnas y de mis alumnos: trabajos monográficos espléndidamente construídos 0 especialmente largos y abstrusos, comentarios de texto llenos de imaginación o maravillosamente disparatados, mensajes didácticos lacónicos y precisos o aparentemente fríos y distantes, síntesis apretadas e imposibles de las cuestiones más complejas, digresiones inverosímiles sobre lo que hay y lo que no hay... En fin, el milagro nuevo del aprendizaje. Sin esta mensajería, oral o escrita, llena de candor y de pasión, sería imposible la comuni- 
cación pedagógica [...] ¡Cuánta alma hay detrás del mensaje estudiantil!» (Retallos, 1992: 143).

Este tapiz conciso de pareceres sitúanos perante o esquema do seu pensamento no tocante ao alumnado. Con el, na "nosa Casa», consonte lle gustaba chamar á Facultade, aínda o estaba a agardar o que cualificou como a experiencia «máis estimulante e gratificante de toda a miña vida académica» (Memoria crítica, 2004: 12), naquel curso 2003-2004 da súa apoteose docente, que xa tivera un profético adianto extra muros no 2001-2002. 0 estudantado que concorreu ao seu despacho no primeiro bienio citado rendeulle unha xenuína homenaxe informal e espontánea, coma se intuíse que se aveciñaba unha mudanza decisiva e sen retorno na súa traxectoria profesional. Logrou algo do que non fomos capaces os membros do departamento ao que pertencía, malia telo intentado, acaso -matino eu agora- sen a suficiente determinación, en varias ocasións. Ende ben, tributáronllo os compoñentes da comunidade universitaria aos que adoito máis vencellado se sentiu e aos que máis amou.

Doe recordar que o educador, o mestre, o compañeiro, o amigo Herminio Barreiro xa non se atopa fisicamente entre nós. Pero calma e aleda saber que a súa memoria se mantén viva e a súa obra será ao cabo imperecedoira. Terémolo arreo a carón de cantos 0 coñecemos. Oxalá saibamos transferir as ensinanzas que nos legou aos que veñan logo. Que mellor ofrenda. Que máis acaída demostración de lembranza e gratitude para quen foi admirado e querido por tantas e tantos, mercé á súa extraordinaria calidade humana e profesional.

Nun día tan sinalado coma o de hoxe, no que se cumpre o 80 aniversario da proclamación da Segunda República, de notorio significado para el e de palmar transcendencia para a historia da educación española, vanme permitir que a miña humilde palabra serva para expresar, dende esta tribuna, un esperanzado desexo, en nome dos asistentes e tamén dos que por motivos diversos fican ausentes. Que a raiola de luz coa que Herminio nos alumeou durante 34 anos acó en Compostela non se apague nin deixe de refulxir xamais.

VIVIU e VIVE!!! 